\title{
Correction to: Sentinel Lymph Node Biopsy and Completion Lymph Node Dissection for Melanoma
}

\section{Sabran J. Masoud, $B S^{1}$}

Jennifer A. Perone, $M D^{2}$

Norma E. Farrow, $M D^{1}$

Paul J. Mosca, MD, PhD, MBA

Douglas S. Tyler, $M D^{2}$

Georgia M. Beasley, MD, MHS ${ }^{1,3, *}$

\section{Address}

${ }^{1}$ Department of Surgery, Duke University, Durham, NC, 27710, USA

${ }^{2}$ Department of Surgery, University of Texas Medical Branch, Galveston, TX, USA

${ }^{*}, 3$ Duke University Medical Center, DUMC Box 3118, Durham, NC, 27710, USA

Email: Georgia.beasley@duke.edu

Published online: 29 August 2019

(C) Springer Science+Business Media, LLC, part of Springer Nature 2019

The online version of the original article can be found at https://doi.org/10.1007/s11864-018-0575-4

Correction to: Curr Treat Options in Oncol (2018) 19:55 https://doi.org/10.1007/s11864-018-0575-4

The original version of this article, which published in Current Treatment Options in Oncology, Volume 19, Issue 11, November 2018, contained an error within the Conflict of Interest statements. It was originally stated that "Norma E. Farrow received support from an NIH T32 grant (T32-CA009111." The grant number listed is incorrect. The correct grant number is T32-CA093245.

The authors apologize to the readers for this error.

\section{Publisher's Note}

Springer Nature remains neutral with regard to jurisdictional claims in published maps and institutional affiliations. 